\title{
ENTRE A ÉTICA E O DIREITO INTERNACIONAL NA SOCIEDADE GLOBAL: DO COSMOPOLITISMO IDEALISTA AO REALISTA
}

\author{
BETWEEN ETHICS AND INTERNATIONAL LAW IN THE GLOBAL SOCIETY:
} FROM THE IDEALIST TO THE REALIST COSMOPOLITANISM

\section{RESUMO}

$\mathrm{Na}$ esteira do ressurgimento do interesse pelas teses cosmopolitas, impulsionados pela revigoração das teses kantianas do direito cosmopolita, este trabalho tem por objetivo ressaltar os pricipais aspectos da obra kantiana utilizados pelos seus comentadores contemporâneos como sendo os fundamentos do dever de cooperação internacional desde uma perspectiva ética e também jurídica. Primeiramente será delineado o desenvolvimento do cosmopolitismo moderno a partir da ideia de um dever ético até o impulso dado a ele por Immanuel Kant na direção da ação política através do direito cosmopolita. Posteriormente serão vistos alguns dos avanços contemporâneos no projeto kantiano quanto ao contexto global.

Palavras-chave: Direito

Internacional;

\begin{abstract}
In the wake of the resurgence of interest on the the cosmopolitan thesis, driven by the reinvigoration of the Kantian idea of cosmopolitan law, this work aims to highlight the main aspects of Kant's work used by his contemporaries commentators as being the foundations of international cooperation desired from both an ethical and legal perspective. Primarily it will be outlined the development of modern cosmopolitanism from the idea of an ethical duty to the impetus given to him by Immanuel Kant in the direction of political action through the cosmopolitan law. Posteriorly, it will be seen some contemporary advances in Kantian project as the global context.
\end{abstract}

Keywords: International Law. Cosmopolitanism. Immanuel Kant

\section{SUMÁRIO}

INTRODUÇÃO; 1. O COSMOPOLITISMO ENTRE A ÉTICA E O DIREITO NA OBRA DE IMMANUEL KANT; 2. LEITURA CONTEMPORÂNEAS DO PROJETO KANTIANO; CONCLUSÃO; REFERÊN

\section{CIAS}

REDESG / Revista Direitos Emergentes na Sociedade Global - www.ufsm.br/redesg v. 3, n. 1, jan-jun/2014 


\section{INTRODUÇÃO}

Ao tomar o Estado-nação como um dado a priori, e ao pensar a organização social e política essencialmente dentro das suas fronteiras, a teoria do direito e do Estado dos séculos XIX e XX contribuiu muito pouco para a compreensão de algumas das questões fundamentais com que se defrontam as democracias liberais contemporâneas.

O processo de globalização econômica e a universalização dos direitos humanos têm exigido do raciocínio político e jurídico respostas político-institucionais que possibilitem uma nova ordenação de suas forças propulsoras com vistas à pacificação, humanização e democratização da e na sociedade global.

Nesta esteira, o cosmopolitismo tem se despontado como uma alternativa políticojurídica, já que reconhece os Estados nacionais como unidades políticas primordiais, da mesma maneira que confere importantes responsabilidades às organizações internacionais. Entretanto, a teoria cosmopolita da democracia parte da premissa de que os seres humanos, como indivíduos, e não como cidadãos, representam unidades fundamentais da preocupação moral e política. Assim, sendo uma tese universalista, o cosmopolitismo entende que todos os seres humanos possuem um igual status moral, razão pela qual ninguém poderia se isentar de suas obrigações de respeitar o status moral igual de todos os outros seres humanos, e ainda mais do que isto, exige que os indivíduos sejam objetos de preocupação de todos.

Transcendendo uma análise meramente moral, importante a contribuição de Immanuel Kant para dotar o cosmopolitismo de força política. Isso acontece através da integração entre a razão pura e a razão prática. Indubitavelmente, a comunicação do moral e do jurídico no pensamento de Kant transfere o projeto cosmopolita de uma simples questão ética para uma questão jurídico/política, sobretudo através da ideia do direito cosmopolita.

O direito cosmopolita poderá, então, ser concebido como um domínio legal, diferenciado do direito estatal e do direito interestatal (lei internacional). Dessa forma, autores contemporâneos, inspirados em Kant, afirmam a existência de uma cidadania cosmopolita, garantidoura de direitos e liberdades não somente pelo Estado-nacional, mas que perpassaria os diversos sistemas jurídicos nacionais. Implica, assim, uma forma peculiar de vínculo jurídico, estabelecido entre o indivíduo e uma nova ordem jurídica, que não se identifica com a legislação do Estado-nação, nem com as leis internacionais. 
Assim, na esteira do ressurgimento do interesse pelas abordagens cosmopolitas, impulsionados pela revigoração das teses kantianas do direito cosmopolita, este trabalho quer investigar quais os pontos do pensamento kantiano são utilizados para sustentar o cosmopolitismo. Assim, o objetivo deste trabalho é ressaltar os principais aspectos do cosmopolitismo na ética e no direito cosmopolitas. Não se trata aqui de fazer uma exegese kantiana a partir do idealismo transcendental, tampouco de comprovar uma fundamentação filosofica do cosmopolitismo, mas tão somente de reconhecer que existe uma tradição de pensamento inspirada em Kant que se debruça sobre as relações internacionais e ressaltar os principais elementos desta tradição.

Assim, na primeira parte deste artigo será delineado o desenvolvimento do cosmopolitismo moderno a partir da ideia de um dever ético até o inpulso dado a ele por Immanuel Kant na direção da ação política, verificando como ele apoia um sistema de justiça internacional na lei cosmopolita e internacional (1). Posteriormente serão vistos os avanços contemporâneos no projeto kantiano quanto ao contexto global, reconhecendo que se trata apenas de um uso instrumental de Kant, feito por autores como Otfried Höffe para a materialização de uma cultura cosmopolita (2).

\section{O COSMOPOLITISMO ENTRE A ÉTICA E O DIREITO NA OBRA DE IMMANUEL} KANT

O cosmopolitismo não é um fenômeno recente. Foi abordado por muitos pensadores de diversas matizes desde a Antiguidade Clássica ${ }^{1}$, onde a ideia de cosmopolitismo se desenvolveu no ideal dos filósofos estoicos, que consideravam os seres humanos como criaturas racionais com direitos universais, sendo, por essa razão, cidadãos cosmopolitas.

Já no iluminismo revolucionário do século XVIII, o cosmopolitismo agregou ao aspecto jurídico e moral, o universalismo político ou cultural que desafiava a particularidade e pretensões totalitárias do Estado-nação, designando o cidadão do mundo como aquele indivíduo que se sente em casa em todos os lugares da Terra.

\footnotetext{
${ }^{1}$ Ainda que, como lembra Otfried Höffe, as virtudes cosmopolíticas em sentido político tenham sido abordadas por Kant de forma incidental e genérica, mesmo em $\dot{A}$ paz perpétua, a qual será analisada a seguir. HÖFFE, Otfried. A democracia no mundo de hoje. Tradução de Tito Lívio Cruz Romão. São Paulo: Martins Fontes, 2005, p. 393.

REDESG / Revista Direitos Emergentes na Sociedade Global - www.ufsm.br/redesg v. 3, n. 1, jan-jun/2014
} 
Porém foi Immanuel Kant, com a obra Idéia de uma história universal de um ponto de vista cosmopolita, de 1784, quem “deu à luz científico-filosófica” ao cosmopolitismo. ${ }^{2}$ Novas contribuições para o cosmopolitismo aparecem em $\dot{A}$ paz perpétua, de 1795, onde Kant apresenta os artigos preliminares à paz perpétua entre Estados, e em Doutrina do Direito, a primeira parte de Metafísica dos Costumes, publicada em 1797.

O filósofo funda a sua teoria moral deontológica em sua concepção da razão prática, que seria a própria capacidade dos seres racionais de determinar o seu agir. Assim, para Kant, essa razão prática constitui a fonte autônoma de todos os princípios e valores morais, de forma que o homem, por ser racional, move a sua ação orientada por valores morais ${ }^{3}$.

As leis morais contribuem para a realização da liberdade humana, sendo que esta liberdade é o único direito inato do homem. De fato, o exercício da liberdade se dá através da razão prática, que impõe princípios norteadores da ação humana, entre eles o imperativo categórico. Esse imperativo categórico subsidia a formulação da comunidade moral ideal, chamada por Kant de reino dos fins, que fornece a base conceitual para a noção de uma comunidade política composta de seres humanos iguais e livres e que encontra no Estado a instituição capaz de promover as condições à realização dos direitos individuais ${ }^{4}$.

Isto está especialmente visível na obra À paz perpétua, onde Kant ressalta que o "estado de natureza" é um estado de guerra, e que a paz deve ser assegurada por estruturas jurídicas institucionais, como o Estado. Confere, dessa forma, relevância ao direito público.

Nesta obra, o intento de Kant, é o de, por meio de nove "proposições", descobrir qual é o propósito da natureza, o qual os homens estariam fadados a seguir. Da mesma forma, Ideia de uma História Universal de um Ponto de Vista Cosmopolita também está dividido em proposições. $\mathrm{Na}$ quinta proposição, Kant aborda a liberdade dos indivíduos para além das fronteiras do

\footnotetext{
${ }^{2}$ KANT, Immanuel. Idéia de uma História Universal de um Ponto de Vista Cosmopolita. São Paulo: Martins Fontes, 2011. Nessa obra, Kant relaciona o desenvolvimento e o melhoramento humano à conduta política adotada pelos indivíduos em relação uns com os outros. A adoção dessa conduta começa a desenhar-se no momento em que o homem, por um ato de vontade, utiliza todo o seu maquinário racional com a finalidade de sair do seu estado de animalidade, pautado nos impulsos sensíveis, e ascende ao estado de sociabilidade, marcado pela busca, sempre inacabada, da moralidade. Em outras palavras, ocorre a incidência da razão prática sobre a ação política.

${ }^{3}$ KANT, Immanuel. Fundamentação da Metafísica dos Costumes. Tradução de Guido Antônio de Almeida. São Paulo: Barcarolla e Discurso Editorial, 2009, p. 85.

${ }^{4}$ Kant afirma que a maneira mais adequada de identificar os imperativos seria como: "regras da habilidade ou conselhos da prudência, ou mandamento (leis) da moralidade. Pois só a lei traz consigo o conceito de uma necessidade incondicional e, na verdade, objetova, e, por conseguinte, universalmente válida". KANT, 2009b, p. 197.
}

REDESG / Revista Direitos Emergentes na Sociedade Global - www.ufsm.br/redesg v. 3, n. 1, jan-jun/2014 
Estado, reconhecendo que "o maior problema para a espécie humana, a cuja solução a natureza a obriga, é alcançar uma sociedade civil que administre universalmente o direito" 5 . Em suma, trata-se da instituição do direito cosmopolita. Este problema, segundo ele, será o último a ser resolvido pela espécie humana, uma vez que a vasta maioria dos homens tem necessidade de líderes (ou senhores), que os obriguem a obedecer à vontade "universalmente válida".

Ancorado em um grande debate sobre as relações entre os diversos povos da Terra e a natureza do "direito das gentes", se natural ou convencional, Kant discorda dos juristas que legitimam a guerra, como Hugo Grócio e Emerich de Vatel, no que se refere à força legal desse direito das gentes:

Tendo em conta a maldade da natureza humana, que pode ver-se às claras na livre relação dos povos (ao passo que no Estado legal-civil se oculta através do governo) é, sem dúvida, de admirar que a palavra direito não tenha ainda podido ser explulsa da política da guerra como pedante e que nenhum Estado tenha ainda ousado manifestar-se publicamente a favor desta última opinião; pois continuam ainda a citar-se candidamente Hugo Grócio, Pufendorf, Vatel e outros (incomodos consolodores apenas!). Embora o seu código elaborado filosófica ou diplomaticamente não tenha a mínima força legal nem a possa também ter (porque os Estados enquanto tais não estão sob nenhuma coação exterior comum). ${ }^{6}$

Kant constata a “insociável sociabilidade dos homens, ou seja, sua tendência a entrar em sociedade que está ligada a uma oposição geral que ameaça constantemente dissolver esta sociedade"7, levando o homem ao mesmo tempo à concórdia e à discórdia. Dessa forma, segundo Kant:

O maior problema para a espécie humana, a cuja solução a natureza o obriga, é alcançar uma sociedade civil que administre universalmente o direito. Como somente em sociedade e a rigor naquela que permite a máxima liberdade e, consequentemente, um antagonismo geral de seus membros e, portanto, a mais precisa determinação e resguardo dos limites desta liberdade - de modo a poder coexistir com a liberdade dos outros. ${ }^{8}$

Assim, "uma sociedade na qual a liberdade sob leis exteriores encontra-se ligada ao mais alto grau a um poder irreversível, ou seja, a uma constituição civil perfeitamente justa deve ser

\footnotetext{
${ }^{5}$ KANT, Immanuel. Idéia de uma História Universal de um Ponto de Vista Cosmopolita. Tradução de Rodrigo Naves e Ricardo R. Terra. São Paulo: Martins Fontes, 2011. p. 10.

${ }^{6}$ KANT, Immanuel. A Paz Perpétua e outros opúsculos. Tradução de Artur Mourão. Lisboa: Edições 70, 2009a., p. 144.

${ }^{7}$ Ibid., p. 08.

${ }^{8}$ Ibid., 2011, p. 10.

REDESG / Revista Direitos Emergentes na Sociedade Global - www.ufsm.br/redesg v. 3, n. 1, jan-jun/2014
} 
a mais elevada tarefa para da natureza para a espécie humana"9. Mas, "o problema do estabelecimento de uma constituição civil perfeita depende do problema da relação externa legal entre Estados e não pode ser resolvido sem que este último o seja”. ${ }^{10}$

Dessa forma, a solução encontrada por Kant é a criação de uma “federação de nações"11, o que alguns autores vão chamar de Estado civil mundial, ou ainda, Estado cosmopolita:

A mesma insociabilidade que obrigou os homens a esta tarefa [estabelecimento de uma constituição civil] é novamente a causa de que cada república, em suas relações externas - ou seja, como um Estado em relação a outros Estados -, esteja numa liberdade irrestrita, e consequentemente deva esperar do outro os mesmos males que oprimiam os indivíduos e os obrigavam a entrar num estado civil conforme leis. ${ }^{12}$

Segundo Katrin Flinkschuh,

Tradicionalmente, teóricos das relações internacionais tem tendido a associar o cosmopolitismo de Kant, isto é, a sua ideia de 'cidadão do mundo' (Weltburger), como um apelo para o estado mundial - uma proposta que, como realistas políticos, eles eram extremamente cautelosos, não por menos devido a implícita perda da soberania estatal. ${ }^{13}$

Assim, Katrin Flinkschuh constata a analogia que Kant faz entre indivíduos e Estados, por serem dois tipos de pessoas morais, ao mesmo tempo que esclarece a ausência de qualquer auto-contradição na expressão Estado mundial:

Desde que Kant traça uma explícita analogia entre indivíduos e estados como dois tipos de pessoa moral, a exigência de que os estados cedem (parte) da sua soberania para se submeter a uma mais alta autoridade não é mais contraditório do que a exigência de que os indivíduos desistam da sua liberdade sem lei para entrar em uma sociedade civil. ${ }^{14}$

\footnotetext{
${ }^{9}$ Ibid., 2011, p. 10.

${ }^{10}$ Ibid., 2011, p. 12.

${ }^{11}$ Ibid., 2011, p. 13.

12 Ibid., 2011, p. 13.
}

13 "Traditionally, international relations theorists have tended to associate Kant's cosmopolitanism, i.e. his idea of 'world citizens' (Weltburger), with a plea for a world state - a proposal which, as political realists, they were extremely wary of, not least because of the implied loss of state sovereignty". FLINKSCHUH, Katrin. Kant and Modern Political Philosophy. Cambridge University Press, 2004, p. 184.

14 "Since Kant draws an explicit analogy between individuals and states as two kinds of moral person, the requirement that states cede (part of) their sovereignty in order to submit to a higher authority is no more self-contradictory than the demand that individuals give up their lawless freedom upon entrance into civil society". FLINKSCHUH, 2004, p. 184-185.

REDESG / Revista Direitos Emergentes na Sociedade Global - www.ufsm.br/redesg v. 3, n. 1, jan-jun/2014 
Entretanto, a autora argumenta que, embora existam leituras divergentes acerca de se tratar de um Estado mundial ou uma associação federativa, impõe-se uma leitura em favor de desta última, não somente por uma questão pragmática (Estados simplesmente não estariam preparados para abrir mão de sua soberania), mas porque os Estados perderiam a sua liberdade ao se submeterem a um Estado mundial, o que contradiria toda a construção kantiana da existência do Direito. Segundo Katrin Flinkschuh:

Nessa leitura, a ideia de um estado mundial contradiz as razões pelas quais ele foi estabelecido nas medidas em que os poderes de coerção de um estado mundial minaria a possibilidade de estados livremente se associarem uns com os outros. Unificação sob um estado mundial seria baseada no medo da coerção, o que é contrário a afirmação de Kant de que uma paz global duradoura deve ser premissa à rejeição, em princípio, da ameaça ou uso da força entre estados. ${ }^{15}$

Então, ao invés de Estado mundial (centralizado e unitário), este Estado civil poderia ser chamado de Estado cosmopolita, que seria uma verdadeira "federação de nações em que todo Estado, mesmo o menor deles, pudesse esperar sua segurança e direito não da própria força ou do próprio juízo legal, mas somente desta grande confederação de nações (Foedus Amphictyonum) de um poder unificado e da decisão segundo leis de uma vontade unificada". ${ }^{16}$

Kant reconhece que, "tão fantástica quanto essa ideia possa parecer, e embora, enquanto tal se preste ao riso no Abée de Saint-Pierre ou em Rousseau (...), é a saída inevitável da miséria em que os homens se colocam mutuamente" ${ }^{17}$. Esse movimento que levou o homem selvagem a renunciar a sua liberdade é um movimento objetivo da natureza humana, que, “depois de várias revoluções e transformações, finalmente poderá ser realizado um dia aquilo que a natureza tem como propósito supremo, um Estado cosmopolita universal". ${ }^{18}$

Note-se que essa Estado cosmopolita mundial desempenha entre os Estados o papel de um imperativo categórico, cujo instrumento de realização é o direito internacional e o direito cosmopolita, construção estas que aparecem no segundo e terceiro artigo da Paz Perpétua como condições positivas para a efetivação da paz, ao lado da existência do direito interno (civil).

\footnotetext{
15 "On this reading, the idea of a world state contradicts the reasons for its establishment in so far as a world state's coercive powers undercut the possibility of states freely associating with one another. Unification under a world state would be based on the threat of coercion, which is contrary to Kant's claim that a lasting global peace must be premised on the rejection in principle of the threat or use of force among states". FLINKSCHUH, 2004, p. 185.

${ }^{16}$ KANT, 2011, p. 13.

17 Ibid., p. 13.

${ }^{18}$ Ibid., p. 19.

REDESG / Revista Direitos Emergentes na Sociedade Global - www.ufsm.br/redesg v. 3, n. 1, jan-jun/2014
} 
Segundo Soraya Nour:

O direito, até Kant, tinha duas dimensões, o direito estatal, isto é, o direito interno de cada Estado, e o direito das gentes, isto é, o direito das relações dos Estados entre si e dos indivíduos de um Estado com os de outro. Em uma nota de rodapé na Paz Perpétua, Kant apresenta uma terceira dimensão: o direito cosmopolita. ${ }^{19}$

Nesse mesmo sentido, Katrin Flinkschuh diz que:

Kant reconhece três níveis, diferentes mas relacionados, em relação ao direito: o "Direito de um estado" especifica relações jurídicas entre pessoas dentro de um mesmo estado; o "Direito das nações" diz respeito as relações jurídicas entre estados; e "o Direito para todas as nações" ou "Direito cosmopolita" concerne as relacões jurídicas entre pessoas e estados estrangeiros. ${ }^{20}$

Assim, ao lado do direito interno de cada Estado, que era o direito político dos homens em um povo (ius civitatis), e do direito internacional, que era o direito das gentes configurado nas relações recíprocas entre os Estados (ius gentium), passa a existir a partir de Kant o direito cosmopolita. Assim, ao direito público e ao direito internacional vem somar-se o direito cosmopolita, e não substituí-los.

Para Soraya Nour trata-se do "direito dos cidadãos do mundo, que considera cada indivíduo não membro de seu Estado, mas membro, ao lado de cada Estado, de uma sociedade cosmopolita"21. Assim, o direito cosmopolita não se confunde com o direito interno ou o internacional, pois considera ao mesmo tempo os homens e os Estados na sua relação externa de influência recíproca, como cidadãos de um Estado universal da humanidade (ius cosmopoliticum).

Segundo Katrin Flinkschuh, o direito cosmopolita não perde relevância por ele não estar vinculado a um Estado mundial:

Se Kant rejeita a ideia de um estado mundial como uma questão de princípio, ou se ele meramente posterga a sua ralização por razões pragmáticas, sem dúvida vai continuar a see ponto de algum debate. Em ambos os casos a fluidez da política global em curso, com o desmembramento de estados individuais, a

\footnotetext{
${ }_{19}^{19}$ NOUR, 2004, p. 54.

20 "Kant recognises three distinct though related levels of rightful relation: the 'Right of a state' specifies relations of Right between persons within a state; the 'Right of nations' pertains to relations of Right between states; and 'the Right for all nations' or 'cosmopolitan Right' concerns relations of Right between persons and foreign states".FLINKSCHUH, 2004, p. 184.

${ }^{21}$ NOUR, 2004, p. 55.

REDESG / Revista Direitos Emergentes na Sociedade Global - www.ufsm.br/redesg v. 3, n. 1, jan-jun/2014
} 
associação semi-federativa e regional entre alguns estados e o vasto aumento do número de agentes globais não estatais tem feito com que os três níveis de direito de Kant estejam atraindo o interesse prático considerável hoje. ${ }^{22}$

Se a existência e a contemporaneidade do direito cosmopolita são inegáveis, questões sobre o alcance do seu conteúdo tem suscitado muitos debates. Segundo Deisy Ventura, o direito cosmopolita de Kant não é um corpus normativo do qual se possa questionar a efetividade ou a factibilidade, mas um princípio regulador das comunicações recíprocas entre os Estados. Segundo ela, "o direito cosmopolita não é direito internacional, ou inter-estatal, ou intergovernamental porque, mais do que reconhecer o indivíduo como sujeito de direito, o situa no fulcro semântico da categoria, como razão de ser e de dever ser"23.

Outra importante baliza do cosmopolitismo é a correspondência entre a "pólis" e a "cosmopólis", o que leva a crer em uma igualdade entre os Estados, no sentido de que uma não estaria acima da outra, mas no mesmo nível, entre iguais. Assim, Kant prenuncia o que mais tarde viria a acontecer, no século XX, com as várias instituições internacionais construídas sobre uma igualdade formal ${ }^{24}$ entre os Estados, que não menosprezaram o papel do Estado como importante ferramenta de organização social e política. Assim, o cosmopolitismo não pressupõe a existência de um Estado supranacional e nem confunde o direito cosmopolita com um direito supranacional.

De fundamental importância neste contexto é o status e o conteúdo do direito cosmopolita, visto que ele opera em um contexto onde não há um Estado mundial que o impõe:

Uma vez que Kant não é mais lido como inequivocadamente endossando a ideia de um estado mundial, o status do cidadão mundial deve mudar em todos os aspectos. Em um estado mundial, a cidadania global presumidamente substituiria a função atual da cidadania dentro de cada estado. ${ }^{25}$

\footnotetext{
22 "Whether Kant rejects the idea of the world state as a matter of principle, or whether he merely postpones its realisation for pragmatic reasons, will no doubt remain a point of some debate. In either case, the fluidity of current global politics, with the break-up of individual states, the semi-federative, regional association between some states, and the vastly increased number of non-state global agents has meant that Kant's three levels of Right are attracting considerable practical interest today". FLINKSCHUH, 2004, p. 186.

${ }^{23}$ VENTURA, 2008, p. 231-232.

24 Ibid., p. 232.

25 "Once Kant is no longer read as unambiguously endorsing the idea of a world state, the status of the world citizen must change as well. Within a world state, global citizenship would presumably replace the current function of citizenship within individual states". FLINKSCHUH, 2004, p. 186.
}

REDESG / Revista Direitos Emergentes na Sociedade Global - www.ufsm.br/redesg v. 3, n. 1, jan-jun/2014 
Ora, o que garantiria a cidadania mundial em um ambiente sem um Estado mundial seria justamente o direito cosmopolita:

Cidadãos globais são cidadão sem um estado mundial que retêm a sua cidadania em relação aos estados individuais de que eles são membros. A ideia da cidadania mundial como uma cidadania sem um estado mundial tem ganhado cada vez mais força entre os debatedores da justiça global, estando isto no contexto da federação europeia, no debate do direito internacional dos direitos humanos ou do direito internacional em geral. ${ }^{26}$

Não há como negar que a premissa para os três direitos (direito estatal, internacional e cosmopolita) é absolutamente a mesma: a recíproca influência física dos homens. Ora, como a Terra não é uma superfície infinita, mas sim fechada sobre si mesma ${ }^{27}$, não se pode evitar a proximidade espacial com outras pessoas, de modo que os habitantes de toda a terra passam a constituir um sistema em que "o ataque a um direito em um lugar da Terra é sentido em todos". 28

Kant é categórico ao afirmar o caráter jurídico do direito cosmopolítico: "trata-se aqui, como nos artigos precedentes, não de filantropia, mas de direito" ${ }^{29}$. Com essa afirmação, Kant se preocupa em dotar de tangibilidade o seu projeto de paz perpétua, negando o caráter utópico que estaria presente nos projetos de paz anteriores, como o de Abeé de Saint-Pierre e Jean Jacques Rousseau:

Mas dirse-á, "jamais os Estados se submeterão a tais leis coercivas; e o projeto de um Estado universal dos povos, a cujo poder se devem sujeitar livremente todos os Estados para obedecer às suas leis, pode soar agradavelmente na teoria de um St. Pierre ou de um Rousseau, mas não vale a pena para a prática: pois, foi também em todos os tempos escarnecido por grandes estadistas e ainda mais pelos chefes de Estado como uma ideia pedante e pueril, saída da escola". Da minha parte, pelo contrário, confio na teoria, que dimana do princípio de direito sobre o que deve ser a relação entre os homens e os Estados, e que recomenda aos deuses da Terra a máxima de sempre procederem nos seus conflitos de maneira a introduzir-se assim um tal Estado universal dos povos e a supor também que ele é possível (in praxi) e que pode existir; mas, ao mesmo tempo,

\footnotetext{
26 "Global citizens are citizens without a world state who retain their citizenship in relation to the individual states of which they are members. The idea of the world citizen as a citizen without a world state has gained increasing currency among discussants of global justice, be this in the context of a European federation, of the international human rights debate, or that of international law in general". FLINKSCHUH, 2004, p. 186.

${ }^{27}$ NOUR, 2004, p. 55.

28 KANT, 2009a, 151.

29 lbid., 152.

REDESG / Revista Direitos Emergentes na Sociedade Global - www.ufsm.br/redesg v. 3, n. 1, jan-jun/2014
} 
confio também (in subsidium) na natureza das coisas que obriga a ir para onde de bom grado não se deseja (...). Do ponto de vista cosmopolita, se persiste também na afirmação: 0 que por razões racionais vale para a teoria, vale igualmente para a prática. ${ }^{30}$

Nesse sentido, elucida Katrin Flinkschuh, afirmando que " o status do direito cosmopolita como 'direito estrito', isto é, externamente executável, portanto sujeito à institucionalização e como implicando obrigações por parte do titular do direito". ${ }^{31} \mathrm{E}$ segue a autora:

Se alguém aceita os direitos cosmopolitas dos indivíduos à hospitalidade como um direito estrito, as obrigações correspondentes e os requisitos para a aplicação da lei institucionalizada impõe restrições à agência internacional que são mais rigorosas do que o conteúdo escasso de Direito cosmopolita pode inicialmente sugerir. Isto não é negar que a concepção de direito cosmopolita de Kant requer alguma extensão nas condições atuais da globalização. Como já foi referido, isto agora é frequentemente feito por meio de uma ligação do direito cosmopolita de Kant às disposições atuais de direitos humanos. ${ }^{32}$

Da mesma forma, na Doutrina do Direito, de 1797, o projeto de paz ganha maior tangibilidade: “Esta ideia racional de uma comunidade pacífica perpétua de todos os povos da Terra (mesmo quando não sejam amigos), entre os quais podem ser estabelecidas relações, não é um princípio filantrópico (moral), mas um princípio de direito”33.

Assim Kant justifica o direito cosmopolita:

A natureza encerrou todos os homens juntos, por meio da forma redonda que deu ao seu domicílio comum (globus terraqueus), num espaço determinado. E, como a posse do solo, sobre o qual o habitante da Terra foi chamado a viver, só pode ser concebida como a posse de uma parte de um todo determinado. Por conseguinte, se uma parte sobre a qual cada um deles tem um direito primitivo, todos os povos estão originalmente em comunidade do solo; não em comunidade jurídica da posse (communio) e portanto de uso ou de reciprocidade desse solo; mas em reciprocidade de ação (commercium) física possível, isto é, numa relação universal de apenas um com todos os demais (relação que consiste a se

\footnotetext{
${ }^{30}$ KANT, 2009a, p. 109.

31 "The status of cosmopolitan Right as a 'strict right', i.e. as externally enforceable, hence as subject to institutionalisation and as entailing obligations on the part of the rights holder". FLINKSCHUH, 2004, p. 187.

32 "If one does accept individuals' cosmopolitan rights to hospitality as a strict right, its corresponding obligations and requirements for institutionalised law enforcement impose constraints on international agency that are more stringent than the meagre content of cosmopolitan Right may initially suggest. This is not to deny that Kant's conception of cosmopolitan Right requires some extension under current conditions of globalisation. As already indicated, this is now often done by means of linking Kant's cosmopolitan Right to current human rights provisions". FLINKSCHUH, 2004, p. 187.

${ }^{33}$ KANT, 2005, p. 201.

REDESG / Revista Direitos Emergentes na Sociedade Global - www.ufsm.br/redesg v. 3, n. 1, jan-jun/2014
} 
prestar a um comércio recíproco); e têm o direito de fazer a experiência, sem que por isso possa um estrangeiro tratá-los como inimigo. Este direito, como a união possível de todos os povos, com relação a certas leis universais de seu comércio possível pode ser chamado de direito cosmopolita (jus cosmopoliticum). ${ }^{34}$

Quanto ao conteúdo deste direito cosmopolita, o terceiro artigo definitivo à paz perpétua assevere que "o direito cosmopolita deve se limitar às condições de uma hospitalidade universal"35. O direito cosmopolita “é estabelecido a partir do princípio de que todos, originalmente, tem o mesmo direito sobre o solo" ${ }^{36} \mathrm{e}$, assim, "ninguém tem mais direito que um outro de estar em um lugar da Terra" ${ }^{37}$. Trata-se de uma verdadeira sociedade global ${ }^{38}$, um vínculo jurídico que não exclui o direito interno e o internacional, mas os agrega conjuntamente com uma terceira dimensão do direito, que vincula diretamente as pessoas de todo o mundo aos Estados estrangeiros. Assim a tarceira característica do direito cosmopolita é justamente expressa neste conteúdo de hospitalidade universal.

Do direito à liberdade tão caro à filosofia política kantiana decorre o "direito de visita" 39 , ou seja "o direito do cidadão da Terra de tentar a comunidade com todos e, para esse fim, de visitar todos os lugares da terra"40 e o "direito de hospitalidade"41 que é o direito de, "na tentativa de se relacionar com o outro, não ser tratado pelo estrangeiro como inimigo". ${ }^{42}$

Observe-se que uma decorrência do fato de o direito cosmopolita ser um direito sem Estado faz com que ele tenha um conteúdo um tanto quanto restrito:

A Doutrina do Direito define direito cosmopolita, ou seja, os direitos dos indivíduos contra um estado estrangeiro, como 'o direito de hospitalidade'. Indivíduos têm o direito de não ser maltratado ou perturbado em suas posses, quando em território estrangeiro. De modo mais geral, eles têm o direito de

\footnotetext{
${ }^{34}$ KANT, 2005, p. 201.

${ }^{35}$ Aqui é importante a ressalva feita por Soraya Nour. Segundo ela, a ideia kantiana de cosmopolitismo é uma severa crítica à atitude dos europeus em relação aos povos de outros continentes. Assim, Kant denuncia os métodos da colonização, em que os europeis se apropriaram de muitas terras pela força. Assim, Kant noa concorda com a colonização do novo mundo e também com a primazaa do comércio nas relaÇões internacionais, reputando como inospitaleira a conduta das potências europeias. NOUR, op. cit., p. 57.

${ }^{36}$ Rever

${ }^{37}$ KANT, 2009a, p. 140.

38 IANNI, 2002.

${ }^{39}$ KANT, 2009a, p. 160.

40 Id., 2003, p. 202.

${ }^{41}$ Id., 2009 a, p. 155.

42 Id., 2005, p. 200.

REDESG / Revista Direitos Emergentes na Sociedade Global - www.ufsm.br/redesg v. 3, n. 1, jan-jun/2014
} 
oferecer se envolver em comércio com o outro ', e o direito 'para tentar estabelecer comunhão com todos, e para este fim, para visitar todas as regiões da terra'. No entanto, o direito de hospitalidade não é o direito de um convidado para ficar o tempo que quiserem, nem é um direito à cidadania desse estado. 0 direito de hospitalidade é estritamente limitado a um direito de residência temporária e o direito de ser tratado com justiça na duração de sua estadia. ${ }^{43}$

O direito cosmopolita é, então, fundamentalmente um direito de visita. Katrin Flinkschuh entende que o conteúdo do direito cosmopolita é mais restrito do que se poderia pensar um ingênuo idealista, sendo restrito ao direito de não ser maltratado ou destituído das suas posses quando um indivíduo estiver em um Estado estrangeiro. Observe que o direito cosmopolita kantiano não dá ao hóspede o direito de permanecer no Estado estrangeiro o tempo que quiser, tampouco atribui ao hóspede a cidadania do Estado visitado da mesma forma que não impõe a este Estado o dever de tratar o estrangeiro como se cidadão fosse.

Como o direito cosmopolita é fundamentalmente um direito de visita, ele não abriga nenhum direito à hospitalidade no sentido de uma determinada obrigação de receber e tratar bem os seus hóspedes. 0 hóspede é alguém que está por pouco tempo numa determina região ou localidade e, por isso, recebe um tratamento especial. Nesse sentido, ele deve obedecer às normas específicas e costumeiras do Estado que o recebe como hóspede.

Essa limitação do direito cosmopolita ao direito de visita se deve ao fato de que, se o direito concedesse a permissão de instalação sobre um território estrangeiro, isso poderia acarretar na violação da soberania da população indígena ${ }^{44}$. Se o direito cosmopolita fosse mais abrangente, diz Kant, ele poderia se transformar em um direito para conquistar e tomar posse, ao invés de somente interagir com outra sociedade. 0 direito cosmopolita propõe, portanto, uma rejeição estridente das formas mais rudimentares de colonialismo.

\footnotetext{
43 "The Rechtslehre defines cosmopolitan Right, i.e. the rights of individuals against a foreign state, as 'the right of hospitality'. Individuals have a right not to be maltreated or disturbed in their possessions when on foreign territory. More generally, they have the right to 'offer to engage in commerce with one another', and the right 'to try to establish community with all, and to this end, to visit all regions of the earth'. However, the right to hospitality is not the right of a guest to stay as long as they please, nor is it a right to citizenship of that state. The right to hospitality is strictly limited to a right to temporary abode and the right to being dealt with justly for the duration of one's stay". FLINKSCHUH, 2004, p. 186.

${ }^{44}$ KANT, 2009a.
}

REDESG / Revista Direitos Emergentes na Sociedade Global - www.ufsm.br/redesg v. 3, n. 1, jan-jun/2014 
E ainda mais do que isso, o direito cosmopolita garante apenas que os cidadão da Terra podem se engajar na interação com qualquer outro Estado, mas não assegura, no entanto, que tal oferta será aceita. 0 Estado ou o povo, para o qual eles se apresentam, não tem qualquer obrigação de permitir a visita. Então, mais que um direito de visita, trata-se de um direito de tentar visita.

Observe-se que não são só direitos que advém da ideia de direito cosmopolita, mas também deveres, já que "o direito de não ser maltratado pelos indivíduos ou governo de um estado estrangeiro acarreta na correspondente obrigação de respeitar as leis do território e de não atacar indivíduos ou o governo do estado o comunidade em questão". ${ }^{45}$

Comprometido com a busca da paz, Immanuel Kant via no direito cosmopolita uma possibilidade de interação pacífica entre os povos, de modo que tal interação se tornaria legal e pública, isto é, o direito cosmopolita deixaria a sua condição inicial de complemento necessário de um código jurídico não escrito e passaria a ser parte integral do direito. Dessa maneira, a humanidade poderia finalmente se aproximar de uma constituição cosmopolita. A interação além-fronteiras tornava-se - para Kant - a condição de possibilidade para o estabelecimento de relações pacíficas entre diferentes Estados.

Declarando que a Constituição civil em cada Estado deva ser republicana e que um federalismo de Estados livres deve fundar o direito das gentes, Kant argumenta que o seu projeto de paz perpétua seria o objetivo último de todas as nações. Dessa forma, o ideal kantiano pressupunha esse mundo de grande interação, reconhecedor da notável influência que os abalos produzidos em um Estado produzem em todos os outros Estados ${ }^{46}$, o que lastreia a aplicação do pensamento kantiano no mundo contemporâneo, onde é grande a interação entre os Estados.

\section{RELEITURAS CONTEMPORÂNEAS DO DIREITO COSMOPOLITA}

\footnotetext{
45 "the right not to be maltreated by the subjects or government of a foreign state entails the corresponding obligation to respect the laws of the land and not to attack subjects or the government of the state or community in question"FLINKSCHUH, 2004, p. 187.

${ }^{46}$ Uma crítica que se poderia fazer ao paradigma kantiano é o seu idealismo. Ocorre que o idealismo já não pode ser visto como uma simples opção retórica. O desenvolvimento já não é um problema só dos pobres, pois a perspectiva ambiental do desenvolvimento, que orienta o desenvolvimento sustentável, transforma o desenvolvimento do Sul na preocupação do Norte - por exemplo, no que se refere à saúde, ao meio ambiente e à segurança.
}

REDESG / Revista Direitos Emergentes na Sociedade Global - www.ufsm.br/redesg v. 3, n. 1, jan-jun/2014 
Existem muitos autores que se autodenominam inspirados na obra de Immanuel Kant. Exemplo notável é a teoria da democracia cosmopolita desenvolvida pelos politólogos David Held e Daniele Archibugi, que esboça um projeto de governança democratizada de múltiplas camadas. Da mesma forma, autores da filosofia-política como Seyla Benhabib levam as normas universais do discurso ético para além das fronteiras do Estado-nação com um forte cunho normativo.

Outra boa discussão do impacto contemporâneo da concepção kantiana de Direito cosmopolita pode ser encontrada na obra de Otfried Höffe e Ulrich Beck. Conscientes de que o projeto kantiano está localizado temporalmente e materialmente no século XVIII, estes autores não caem na tentação de "aplicar a proposta de Kant à contemporaneidade", mas tão somente se inspiram nesta tradição de pensamento para enfrentar os problemas contemporâneos da organização social e política.

Na obra A democracia no mundo de hoje, Otfried Höffe, desenvolve uma teoria da política aplicada às relações internacionais, que tem por base aquilo que ele mesmo chama de antropologia transcendental, que seria aquele conjunto de condições que determinam os “interesses transcendentais" comuns a todos os homens ${ }^{47}$. Esses interesses transcendentais traduzem as necessidades originárias comuns aos seres humanos, e formam um contrato original, fundamentado no individualismo legitimador, anterior ao Estado. Este primeiro princípio de justiça é um imperativo jurídico universal, já que “o direito opõe-se à arbitrariedade pessoal e à violência pessoal, devendo, exatamente, por esse motivo, dominar em todos os lugares entre os homens" ${ }^{48}$. O Estado seria, para Höffe, um segundo contrato jurídico que tem a tarefa apenas de legitimar aqueles direitos humanos que já existiam antes mesma da existência desse Estado ${ }^{49}$.

E ainda, além da comunidade jurídica originária e secundária, Höffe advoga a existência de uma terceira categoria jurídico institucional, a qual ele chama de República Mundial complementar, que não deve ser confundida, assim como não devia ser confundido o projeto kantiano, com um Leviatã mundial.

\footnotetext{
${ }^{47}$ HÖFFE, 2005, p. 54-58.

${ }^{48}$ HÖFFE, 2005, p. 63.

${ }^{49}$ HÖFFE, 2005

REDESG / Revista Direitos Emergentes na Sociedade Global - www.ufsm.br/redesg v. 3, n. 1, jan-jun/2014
} 
O cerne do estudo de Höffe reside em uma organização normativa, centrada mais precisamente na moral do Direito. Assim Höffe justifica e sintetiza a sua proposta normativa universal:

Considerando-se a Economia, a Ciência, a Medicina, a Tecnologia e a Cultura, e ainda outros fatores, tais como corrents migratórias, problemas ambientais e até mesmo o terrorismo e o crime organizado, vê-se despontar uma necessidade de ação que nõa se atém a fronteira entre Estados. Quando a necessidade de ação se torna global, toma forma a idéia de um Estado igualmente global, uma ordem jurídica e estatal de natureza internacional que, graças à auto-organização enfática, se estabelece como democracia global, como República Mundial ${ }^{50}$.

É justamente nesse contexto de hipercomplexidade e interação ao extremo que vão surgir os problemas contemporâneos que exigem soluções jurídicas e institucionais à organização social e política. Nesse contexto os desafios à governança aumentam de envergadura quando, sob o ponto de vista externo, constata-se a globalização econômica e a universalização dos direitos humanos, a mundialização das instituições e das relações jurídicas. A Teoria do Direito, dessa forma, é desafiada a incluir em sua semântica a problemática das ordens jurídicas plurais e globais $^{51}$. Entre esses desafios, segundo Otfried Höffe, está a superação de um “cosmopolititsmo exclusivo" 52 , vinculado a um projeto hegemônico de globalização. Trata-se de construir uma ordem mundial por meio do equilíbrio de poderes através da cooperação voluntária dos Estados ou por meio da democratização dos Estados nacionais.

Otfried Höffe vem defendendo a ideia de uma República Mundial entendida como um Estado mínimo, subsidiário e federal. Não se trata de uma teoria abstrata, mas uma teoria saturada reflexivamente por meio de pormenores concretos.

Höffe fala de uma globalização ("crescimento e consolidação das relaçxões sociais internacionais" ${ }^{53}$ ) no plural, para além des transformações econômicas, e a descreve em três dimensões da comunidade global comum: comunidade global de violëncia, comunidade de cooperação e comunidade de miséria e sofrimento. Esses fenômenos globais ocorridos em uma parte do mundo, faz-se sentir em todas as partes do mundo.

É a partir dessas três dimensões que surge a necessidade de ação global que os Estados individuais não conseguem realizar sozinhos. Trata-se da "República Mundial complementar, de

\footnotetext{
${ }^{50}$ HÖFFE, 2005, p. 01.

${ }^{51}$ NEVES, Marcelo. Entre Têmis e Leviatã: uma relação difícil. São Paulo: Martins Fontes, 2006. p. 261.

52 HÖFFE, 2005, p. 395.

53 Ibid., p. 06.

REDESG / Revista Direitos Emergentes na Sociedade Global - www.ufsm.br/redesg v. 3, n. 1, jan-jun/2014
} 
caráter subsidiário e federativo, [que] por voltar-se sobremaneira para uma abertura global e por reconhecer os direitos dos Estados, a democracia global está apta a escapar do perigo de um "Leviatã global"

Höffe legitima a República Mundial no fato de que tanto o cidadão do mundo quanto os Estados individuais devem contribuir comumente para a sua legitimação, firmando um duplo contrato republicano mundial, o qual é visto a partir da teoria do contrato social. Todos os poderes da república mundial proveem, portanto, de seu “duplo povo: da comunidade de todos os homens e da comunidade de todos os Estados".

Inspirado na ideia de federalismo que está implicada nos escritos políticos de Kant, que contém como elemento central a ausência da coerção, defende a existência de um Estado de povos, isto seria a República Mundial.

Conforme verificou-se na primeira parte desse artigo, a concepção kantiana de uma federação de Estados livres não deve ser confundida com a defesa de um Estado mundial. Tratase de uma distinção imprescindível para dar fôlego ao projeto cosmopolita na contemporaneidade, já que, os cosmopolitas têm sido considerados como proponentes de um Estado mundial. O cosmopolitismo, entretanto, não é inerentemente contrário ao Estado per se ou à sua versão moderna do Estado-nação. O cosmopolitismo está geralmente preocupado com o desenvolvimento de vários modos de governança - do local, estatal e global -, com o objetivo de facilitar os direitos e interesses de indivíduos que seres humanos.

Nesse sentido vai o projeto de Otfried Höffe:

Em vez de dissolver os Estados nacionais, é recomendável que a República Mundial siga o realismo e reconheça sua própria importância restante, que todavia se mostra atenuada quando comparada ao realismo. O Estado Mundial nõa deve ser instaurado como uma instituição estatalmente homogênea nem como um Estado unitário e central. Em vez disso deverá ser erigido como uma liga de Estados que, por sua vez, preserve um caráter de Estado, de um Estado confederado ${ }^{55}$

Assim como no primeiro contrato, segundo Höffe, a realização dos interesses transcendentais se daria através da justiça comutativa transcendental, que administraria os sujeitos a parir de critérios universalmente aceitos, como a igualdade e a reciprocidade. Tanto

\footnotetext{
54 Ibid., p. 03.

${ }^{5}$ Ibid., p. 343.

REDESG / Revista Direitos Emergentes na Sociedade Global - www.ufsm.br/redesg v. 3, n. 1, jan-jun/2014
} 
os Estados nacionais democratizados quanto a República Mundial Federal devem sustentar o imperativo jurídico universal de proteção aos direitos positivados.

Não se pode ignorar a existência de um conjunto de instâncias jurisdicionais subsidiárias às estatais, como as regionais e internacionais, que colocam em cheque a estatalidade das soluções dos $\operatorname{conflitos}^{56}$. Trata-se de um fenômeno relativamente recente que provoca a porosidade/permeabilidade do direito interno, internacional e cosmopolita, mas que acaba por atingir também as demais jurisdições que não só as estatais.

Assim, a partir da perspectiva de Höffe, percebe-se que muitos dos temas contemporâneos das relações internacionais são essencialmente kantianos, como a sociedade civil global, as instituições jurídicas internacionais (que ganharam a pauta dos estudos internacionais com o surgimento das organizações internacionais), o cosmopolitismo (que funda a noção de direitos humanos e a própria ideia de cooperação internacional) e também o princípio da publicidade, visto como ênfase na ordem pública.

Igualmente, a cooperação internacional nos dias de hoje é, em boa medida, um tema kantiano, já que visa ao reconhecimento dessa ideia cosmpolítica, de grande interação social que forma uma verdadeira comunidade de interesses comuns. Portanto, ainda que esse tema permitisse afirmar a existência de uma cooperação interessada/interesseira, parece mais apropriada falar que ele implica uma cooperação fundada em interesses comuns a toda a humanidade (paradigma kantiano).

No pensamento de Immanuel Kant, a hospitalidade universal (ainda que estritamente restrita) é dever jurídico, configurado em oposição a um direito subjetivo. Trata-se de ter direito à face da terra, ou seja, ter direito, mesmo sendo estrangeiro, a não ser tratado como inimigo - este é o conteúdo do terceiro artigo definitivo para a paz perpétua. Para Kant:

hospitalidade significa aqui o direito de um estrangeiro a não ser tratado com
hostilidade em virtude de sua vinda ao território de outro. Este pode rejeitar o
estrangeiro, se isso puder ocorrer sem a ruína dele, mas enquanto o estrangeiro
se comportar amistosamente no seu lugar, o outro não deve confrontar com
hostilidade. Não existe nenhum direito de hóspede sobre o qual se possa basear

${ }^{56}$ No plano internacional, por exemplo, funciona a Corte Internacional de Justiça em Haia. No plano
supranacional atua o Tribunal de Justiça da Comunidade Européia. Em âmbito regional a Corte
Interamericana de Direitos Humanos. Otfried Höffe propõe uma República Mundial subsidiária e, segundo
ele, no campo da Justiça poderão existir duas esferas de jurisdição. Os Tribunais Internacionais que se
destinariam a solucionar os litígios entre os Estados e a República Mundial e os Tribunais de Direito
Cosmopolita com competência para atuar nos casos em que os Estados tenham cometido ilícitos contra os
direitos humanos. HÖFFE, 2005, p. 428 . REDESG / Revista Direitos Emergentes na Sociedade Global - www.ufsm.br/redesg v. 3, n. 1, jan-jun/2014 
esta pretensão (para isso seria preciso um contrato especialmente generoso para dele fazer um hóspede por certo tempo), mas um direito de visita, que assiste todos os homens para se apresentar à sociedade, em virtude do direito de propriedade comum da superfície da terra, sobre a qual, enquanto superfície esférica, os homens não podem estender-se até o infinito mas devem finalmente suportar-se uns aos outros, pois originariamente ninguém tem mais direito do que outro a estar num determinado lugar da Terra ${ }^{57}$.

Esse dever de hospitalidade universal de que fala Kant afirma que não existe, segundo o direito das gentes, em cada uma das soberanias independentes, o poder absoluto de recusar a aplicação de leis estrangeiras sobre o seu próprio território. Ora, o conceito de independência de um Estado, ser moral, não podia ser exagerado a ponto de autorizar a violação dos direitos de outro Estado, e mais do que isto, de obstaculizar a prestação jurisdicional transfronteiriça, por exemplo.

Note-se que este "estreitamento" ao nacional, que deve ser superado, e o "alargamento" ao internacional, que deve ser alcançado, decorrem, em boa medida, da prática da solidariedade que, pode-se dizer, radica no coração da idéia de "mentalidade alargada", na medida em que essa somente se realiza em consideração ao "outro", mas também exige um esforço de imaginação, um tipo de "pensamento nômada".

Deveria haver, então, uma troca corrente e permanente entre os diversos Estados igualmente soberanos, e mesmo entre os diversos planos normativos internacional, regional e nacional, poderia fomentar uma "fertilização recíproca" entre esses planos. Ora, trata-se de reconhecer que o direito, no seu sentido lato, filosófico, não se vincula ao caráter estatal, no sentido tradicional e restrito, mas está aberto aos outros Estados e aos demais planos normativos, como sublinha Otfried Höffe. ${ }^{58}$

Nesse sentido reside a importância do Höffe, que, ao atualizar o pensamento kantiano aplicando-o ao fenômeno internacional contemporâneo, delineia as bases do cosmopolitismo contemporâneo, que deve ser capaz de orquestrar os fenômenos da globalização econômica e da universalização dos direitos humanos.

Quando Höffe desenvolve a ideia de uma internacionalização plural, a influência kantiana na sua obra fica mais evidente. Segundo Höffe, na integração entre a esfera local e a internacional, e entre as esferas locais, está a importância da ressignificação do modelo estatal moderno até a reconstrução de uma comunidade de Estados cosmopolitas. Para ser cidadão do

\footnotetext{
${ }^{57}$ KANT, 2009a, p. 148.

${ }^{58}$ HÖFFE, 2005.

REDESG / Revista Direitos Emergentes na Sociedade Global - www.ufsm.br/redesg v. 3, n. 1, jan-jun/2014
} 
mundo, não é crível que se renuncie às identidades locais, que constituem, indubitavelmente, fonte de riqueza e vitalidade para as comunidades. A proposta de Höffe destaca o cosmopolitismo graduado:

0 estado mundial que, como consequencia do imperativo legal e político universal está confiada à humanidade em sentido jurídico-moral, deve ser estabelecido como uma república mundial complementar, subsidiária e, ademais, federal. Dentro dela seremos cidadãos do mundo, mas não em sentido exclusivo, senão complementar. 0 conceito exclusivo responde àquele cosmopolitismo que (...) nos coloca para a frente da vida política concreta; e, geralmente, com um sentimento de superioridade moral, ele diz que não é alemão, francês ou italiano, mas apenas cidadão do mundo. Aqui aparece um estado mundial tomando o lugar dos Estados individuais, e o direito cosmopolita irá substituir o direito civil nacional; neste Estado mundo homogêneo, globalista, se é cidadão do mundo, em vez de um cidadão de um Estado. ${ }^{59}$

Mesmo se pensando o cosmopolitismo como uma utopia, ele apresenta-se como uma possibilidade frente aos dias atuais, na medida em que seus princípios são necessários à própria natureza humana. O reconhecimento da alteridade, da dignidade e solidariedade, com certeza apresentam-se como elementos fundamentais ao futuro da humanidade.

É inegável que a globalização afeta as premissas em que se funda o tradicional modelo de Estado e de direito. Nesse sentido, Otfried Höffe entende que igualmente o conceito de cidadania deve ser modificado para abarcar a "cidadania mundial" ou "cidadania cosmopolita".

Höffe diferencia três graus de cidadania mundial:

Considere-se cidadão mundial ou cosmopolita aquele que não se atém à fronteiras, que se desloca por todo o mundo, porém que se sente - mais ou menos - em casa por todas as partes por onde anda. Na medida em que conserva sua língua, sua cultura e seus costumes, mas se deixa levar pela língua franca (antigamente era o grego, hoje em dia é o inglês), não passa de um cosmopolita de primeiro grau: viajante mundial, que, mesmo no estrangeiro, não abre mão de seus vínculos locais e nacionais. Só virá a ser um cidadão mundial mais sofisticado, um cosmopolita de segundo grau, se alcançar aquela abertura para o

59 "El Estado mundial que, como consequência del imperativo jurídico y politico universal está
encomendado a la humanidad en sentido juridico-moral, ha de ser instaurado como una república mundial
complementária, subsidiaria y, además, federal. Dentro de ella seremos ciudadanod del mundo, mas no en
sentido exclusivo sino complementario. El concepto exclusivo responde a aquel cosmopolitismo que (...)
nos fija a estar frente a la vida política concreta; y, por lo regular un sentimiento de superioridad moral,
dice él que no es alemán, francés o italiano, sino unicamente ciudadano del mundo. Aquí aparece un
Estado mundial ocupando el lugar de los Estados particulares, y el derecho cosmopolita viene a sustituir el
derecho civil nacional; en ese Estado mundial homogéneo, globalista, se es ciudadano del mundo en lugar
de ciudadano de un Estado". HÖFFE, 2000, p. 247-248. REDESG / Revista Direitos Emergentes na Sociedade Global - www.ufsm.br/redesg v. 3, n. 1, jan-jun/2014 
mundo que o faça perceber o estrangeiro, reconhecendo-o com igualdade de valor. Em um sentido mais intenso, cidadão mundial é aquele que leva sua própria cultura a um outro país, mas se deixa marcar pela nova cultura e não abdica das novas características após o retorno a sua terra natal. A título de exemplo, pode-se citar um professor de Filosofia alemão Eugen Herrigel (1948), que ensinava Filosofia grega e alemã no Japão, todavia a prendia a alta arte do arco e flecha com um mestre zem-budista e continuou a praticá-la mais tarde na Alemanha. No entanto, mesmo esse cidadão mundial de terceiro grau permaneceu cidadão mundial em um sentido pré-político. Por outro lado, no entendimento político, o cidadão mundial é membro de um Estado que abrange todos os seres juridicamente capazes no mundo inteiro ${ }^{60}$

Essa nova ideia de cidadania é justificada no fato de que, atualmente os direitos humanos não têm pátria nem país, ao contrário, caracterizam-se pela universalidade. 0 importante é ressaltar que a cidadania mundial não exclui a cidadania de um país, mas deve conviver com ela, no que se poderia chamar de dupla natureza jurídica da cidadania ${ }^{61}$.

Em termos comparativos, há uma notável semelhança entre os projetos de Kant e de Höffe que constitui-se no fato de que ambos os filósofos querem a paz - paz mundial como paz perpétua - que deve ser realizada através do direito. Do mesmo modo, os dois também concordam que o equilíbrio das relações de poder não é suficiente para uma paz assegurada e estável devido à fragilidade. Assim, encontra-se em Kant a exigência de que "a constituição civil em cada Estado deve ser republicana". Essa exigência republicana em Kant lembra a exigência democrática em Höffe que se expande também ao nível internacional, assim, ele fala de uma exigência democrática mundial.

Mas não há somente semelhanças entre os dois autores. Uma diferença entre está no fato de que Kant se contentou com uma simples “liga de nações” que não é nenhum Estado mundial, mas uma "federação de Estados livres", e, assim, deixou de lado o argumento a favor de uma república mundial ${ }^{62}$. Devido ao tamanho e à complexidade das atividades, a república mundial tornaria a atividade governamental impossível, as leis perderiam o seu efeito e ela se arruinaria em um “despotismo sem alma” e sucumbiria, por fim, em anarquia.

Para Höffe, Kant deixou-se dissuadir pelos argumentos pragmáticos de sua lógica e não viu que apenas um Estado mundial ultra mínimo com competências limitadas cumpriria a sua

\footnotetext{
${ }^{60}$ HÖFFE, 2005, p. 394.

${ }^{61}$ Idem., p. 398.

${ }^{62}$ KANT, 2009a, p 143.

REDESG / Revista Direitos Emergentes na Sociedade Global - www.ufsm.br/redesg v. 3, n. 1, jan-jun/2014
} 
analogia contratual da superação do estado de natureza ${ }^{63}$. Em que pese ambos os filósofos se utilizem dessa analogia para pensar os o estado de natureza, ambos chegam a resultados diferentes: uma federação de Estados livres em Kant, e um Estado mundial mínimo, em Höffe. Entretanto, ambos acreditam na importância da criação de um direito cosmopolita.

Outro autor imprescindível para tratar do direito cosmopolita é Ulrich Beck, para quem, a realidade tornou-se global e cosmopolita. Exemplos disso são o perigo terrorista que desconhece fronteiras geográficas, os protestos pacifistas em escala global através dos meios de comunicação, que nós colocam todos, enquanto seres humanos, em uma sociedade de risco global. ${ }^{64}$

Ainda que advogue às teses cosmopoliticas, importante ressaltar a crítica feita por Beck à Kant, no sentido de que, segundo ele, o pensamento kantiano não criou um novo campo semântico para o direito cosmopolita, tampouco uma nova metodologia. Segundo Beck, Kant contentou-se em transpor categorias estatais, como federalismo, constituição e cidadania, para a dimensão política mundial ${ }^{65}$. Assim, Beck assevera que Kant pretendia criar uma espécie de cosmopolitismo estatalista. ${ }^{66}$

Beck desenvolve a tese de que atualmente vive-se em uma sociedade de risco caracterizada pela "impossibilidad de prever externamente las situaciones de peligro (...). Los riesgos son el producto histórico, la imagen refleja de las acciones humanas y de sus omisiones, son la expresión del gran desarollo de las fuerzas productivas” ${ }^{\prime 67}$. Ainda, de maneira mais geral:

Por paradoxal que possa parecer, a resistência mista contra à globalização produz globalização política, algo que se observa cada vez mais. A globalização da política, da economia, do direito, da cultura, as redes de comunicação excita os ânimos, e a opinião pública internacional se mantêm constantemente inflamada pelo pavor que produzem os riscos globais ${ }^{68}$

\footnotetext{
${ }^{63}$ HÖFFE, 2005, p. 301.

64 BECK, Ulrich. La mirada cosmopolita o guerra es la paz. Traduccion de Bernardo Moreno Carillo. Barcelona: Paidós, 2005, p. 10

${ }^{65}$ Id., Quiest-ce que le cosmopolitisme?, Paris: Flammarion, 2006a, part. p. 93-95.

${ }^{66} \mathrm{Em}$ defesa de Kant, Deisy Ventura argumenta: "Mas como esperar que um iluminista, filho do século XVIII, combatesse a barbárie, senão pela afirmação de um Estado constitucional republicano em pleno frescor histórico? Já os filhos do século XXI, serão obnubilados pelas Luzes? Ora, um direito cosmopolita do nosso tempo não poderia mesmo ser o kantiano, do mesmo modo que Kant não poderia antecipar a ótica ou a metódica cosmopolítica, imprescindível à compreensão da globalização econômica". VENTURA, 2008, p. 250.

${ }^{67}$ Id. La sociedad del riesgo. Hacia una nueva modernidad. Traducción de Jorge Navarro, Daniel Jiménez e Rosa Borrás. Barcelona: Paidós, 2006b, p. 303.

68 "Por paradójico que pueda parecer, la resistencia mista contra la globalización produce globalización política, algo que se observa cada vez más. La globalización de la política, la economia, el derecho, las REDESG / Revista Direitos Emergentes na Sociedade Global - www.ufsm.br/redesg v. 3, n. 1, jan-jun/2014
} 
Beck adverte que, embora os termos globalização e cosmopolitismo tenham diversos significados atribuídos por diferentes doutrinadores, eles não se confundem. Enquanto a globalização está vinculada a desterritorialização econômica, o cosmopolitismo relaciona-se a um processo multidimensional que altera a percepção da relação dos indivíduos com os Estados, que visa modificar a história dos mundos sociais e, para tanto, ressalta a importância dos Estados nesse contexto. Assim, o cosmopolitismo não quer substituir o nacionalismo. Ao contrário, a ideia da busca de democracia e do reconhecimento internacional dos direitos humanos, tão caras ao cosmopolitismo, necessita de um solo estatal. ${ }^{69}$

Segundo Ulrich Beck, a diferença básica entre globalização e cosmopolitismo está no fato de que este abarca a ideia de patriotismo, vinculando-se à ideia de Estado. Por isso ele qualifica, assim como Höffe, o cosmopolitismo como realista ${ }^{70}$, que considera o Estado como ente essencial para um mundo que está aí para ser constantemente reconstruído. Assim, um olhar cosmpolita significa que, "en un mundo de crisis globales y de peligros derivados de la civilización, pierden su obligatoriedad las viejas diferenciaciones entre dentro e fuera, nacional e internacional". ${ }^{71}$

Para Octavio lanni, a globalização representa um novo ciclo de expansão do capitalismo moderno, como modo de produção e processo civilizatório de alcance mundial ${ }^{72}$. Nesse esquema, frequentemente a globalização nega o Estado, ou, ao menos, prescinde dele. Dessa perspectiva, na globalização os Estados e instituições públicas são deixadas de lado para a prevalência dos interesses privados de mercado, exatamente o oposto da ideia kantiana de compromisso ético republicano.

Assim, na esteira kantiana, a expressão cosmopolitismo abarca inúmeras correlações de interesses nacionais e pós-nacionais recíprocos. Beck resgata uma serie de exemplos que relaciona interesses aparentemente díspares, como o da sociedade civil com os governos, dos

culturas, las redes de comunicación e interacción excita los ánimos, y la opinión pública internacional se mantiene constantemente inflamada por el pavor que producem los riesgos globales”. Ibid., p. 303.

${ }_{70}^{69}$ BECK, 2005, p. 19.

${ }^{70}$ Ibid., p. 10.

71 Ibid., p. 19.

72 IANNI, 2007, p. 11.

REDESG / Revista Direitos Emergentes na Sociedade Global - www.ufsm.br/redesg v. 3, n. 1, jan-jun/2014 
governos com as grandes empresas e das próprias empresas multinacionais com a sociedade civil. $^{73}$

Para Beck, a novidade política do cosmopolitismo não é supremacia do pós-estatal sobre o estatal, mas a associação entre as diversas ordens jurídicas normativas coexistentes no processo de governança contemporâneo. Trata-se de uma ordem multidimensional e multidirecional, global, que se volta ora contra indivíduos, contra empresas multinacionais e ora contra governos nacionais. Nesse sentido diz Ulrich Beck:

\begin{abstract}
as atuações das companhias internacionais e dos governos nacionais sofrem a pressão de um espaço público mundial. A participação individual-coletiva no contexto global é por esta razão decisiva e notável: o cidadão identifica no consumo a senha que autoriza a intervir politicamente em qualquer hora e local. No boicote se reuniram e se associaram a sociedade ativa de consumo e a democracia direta - em todo o planeta ${ }^{74}$.
\end{abstract}

Assim, pode-se afirmar, que, na esteira de Beck, se o Leviatã foi o baluarte da organização social e política na modernidade, não o é mais na contemporaneidade. Somente por meio da cooperação e da procura por conexões de interesses nacionais, internacionais e transnacionais será possível avançar na própria busca pelo sentido do cosmopolitismo contemporâneo.

É precisamente nessa seleção de interesses que se apresenta um quadro novo em torno do cosmopolitismo, aproximado ao modelo elaborado por Kant, desenvolvido em $A$ paz perpétua em que se formula a necessidade da construção de um direito cosmopolita afim de implementar a democracia no mundo de hoje. Vale dizer, um direito cosmopolita que valorize os homens, os Estados, as organizações internacionais, os interesses privados transnacionais em uma relação de interferência mútua.

\title{
CONCLUSÃO
}

Em que pese o denso padrão de interconexões globais - que começou a formar-se na fase inicial de expansão da economia mundial e da formação do Estado moderno ${ }^{75}$-, a teoria

\footnotetext{
${ }^{73}$ BECK, Ulrich. O que é globalização. Equívocos do globalismo - respostas à globalização. Tradução de André Carone. São Paulo: Paz e Terra, 1999, p. 133.

${ }^{74}$ Ibid., p. 129-130.

${ }^{75}$ WALLERSTEIN, Immanuel. The Modern World-System. New York: Academic Press, 1974

REDESG / Revista Direitos Emergentes na Sociedade Global - www.ufsm.br/redesg v. 3, n. 1, jan-jun/2014
} 
moderna do Estado soberano supõe a idéia de uma "comunidade nacional de destino": uma comunidade que se governa a si própria e determina seu próprio futuro. Essa idéia é questionada fundamentalmente pela natureza do padrão das interconexões globais e pelas questões que devem ser enfrentadas pelo Estado na contemporaneidade. As comunidades nacionais de modo algum "programam" com exclusividade as ações, decisões e políticas de seus governos e esses de modo algum simplesmente determinam o que é justo ou apropriado apenas para os seus cidadãos.

A partir da filosofia estóica, o cosmopolitismo afirma que toda a humanidade constitui uma única comunidade e, conseqüentemente, de que todas as pessoas possuem um status moral igual ao nosso. Mas na modernidade, o cosmopolitismo deixou de ser um pouco mais do que uma visão geral ética de mundo, que falhou em oferecer qualquer concepção concreta de normas, agentes e instituições de uma comunidade política global, passando a ser um dever jurídico componente de um projeto genuinamente político e global.

Kant foi o resposável por vincular as teorias do Direito e do Estado com o cosmopolitismo, de forma que a partir da modernidade, o cosmopolitismo deixou de ser a mera ideia de um dever ético e foi inpulsionado na direção da ação política, apoiando um sistema de justiça internacional na lei cosmopolita e internacional. Posteriormente foram vistos os avanços contemporâneos no projeto kantiano quanto ao contexto global, reconhecendo o uso das ideias kantanas para inspirar a filosofia política contemporâne, notadamente autores como Otfried Höffe e Ulrich Beck, que se preocupam em dar tangibilidade de uma cultura cosmopolita reconhecedora da pluralidade de fontes jurídicas normaticas e de instituiçoes tomadoras de decisões, o que importa conceber o mundo de forma cosmopolita.

Assim, tanto em kant quanto em Höffe, a humanidade é composta por um conjunto de seres humanos, os quais deveriam considerar-se membros de um todo maior, como membros de uma mesma e única comunidade. $\mathrm{E}$ como todos pertencem a essa mesma e única comunidade - a comunidade dos seres racionais - todos eles deveriam conduzir as suas vidas de acordo com os mesmos princípios.

\section{REFERÊNCIAS}

BECK, Ulrich. $O$ que é globalização. Equívocos do globalismo - respostas à globalização. Tradução de André Carone. São Paulo: Paz e Terra, 1999. 
- La mirada cosmopolita o guerra es la paz. Traduccion de Bernardo Moreno Carillo. Barcelona: Paidós, 2005.

. Qu'est-ce que le cosmopolitisme? Paris: Flammarion, 2006a.

. La sociedad del riesgo. Hacia una nueva modernidad. Traducción de Jorge Navarro, Daniel Jiménez e Rosa Borrás. Barcelona: Paidós, 2006b.

. O que é globalização. Equívocos do globalismo - respostas à globalização. Tradução de André Carone. São Paulo: Paz e Terra, 1999.

FLINKSCHUH, Katrin. Kant and Modern Political Philosophy. Cambridge University Press, 2004. HÖFFE, Otfried. Derecho Intercultural. Traducción de Rafael Sevilla. Barcelona: Gedisa, 2000.

. A democracia no mundo de hoje. Tradução de Tito Lívio Cruz Romão. São Paulo: Martins Fontes, 2005.

IANNI, Otavio. A sociedade global. Rio de Janeiro: Civilização Brasileira, 2002.

. A era do globalismo. Rio de Janeiro: Civilização Brasileira, 2007.

KANT, Immanuel. Doutrina do Direito. Tradução de Edson Bini. 3. ed. São Paulo: Ícone, 2005.

2009a.

. A Paz Perpétua e outros opúsculos. Tradução de Artur Mourão. Lisboa: Edições 70,

. Fundamentação da Metafísica dos Costumes. Tradução de Guido Antônio de Almeida. São Paulo: Barcarolla e Discurso Editorial, 2009b.

. Idéia de uma história universal de um ponto de vista cosmopolita. São Paulo: Martins Fontes, 2011.

NEVES, Marcelo. Entre Têmis e Leviatã: uma relação difícil. São Paulo: Martins Fontes, 2006.

NOUR, Soraya. À paz perpétua de Kant: Filosofia do direito internacional e das relações internacionais. São Paulo: Martins Fontes, 2004.

VENTURA, Deisy. Hiatos da transnacionalização na nova gramática do direito em rede: um esboço de conjugação entre estatalismo e cosmopolitismo. STRECK, Lênio Luiz; MORAIS, José Luis Bolzan de et al (orgs.). Constiuição, sistemas sociais e hermenêutica. Porto Alegre: Livraria do Advogado; São Leopoldo: UNISINOS, 2008.

WALLERSTEIN, Immanuel. The Modern World-System. New York: Academic Press, 1974

Recebido em: 17/05/2014 / Revisões: 25/11/2014 Aprovado em: 17/12/2014

REDESG / Revista Direitos Emergentes na Sociedade Global - www.ufsm.br/redesg v. 3, n. 1, jan-jun/2014 